\title{
Uncontrollable water deliveries and subsequent finickiness
}

\author{
ELISSA C. FERGUSON and R. F. SOAMES JOB \\ University of Sydney, Sydney, Australia
}

\begin{abstract}
The present experiment investigated the alteration of ingestive behaviors as an outcome of exposure to uncontrollable water deliveries in order to examine the mechanisms underlying finickiness. The experiment employed a single treatment session during which rats were exposed to response-contingent, response-independent, or no-water deliveries in a triadic design. Subsequent two-bottle tests (quinine vs. water) conducted in the treatment apparatus revealed finickiness about the novel, bitter quinine solution in rats previously exposed to uncontrollable water deliveries. Thus, finickiness does not depend on the fear of aversive events, such as shock, but may be explained in terms of stress induction. The persistence of the finickiness effect for the 4 days of testing supports the interpretation that finickiness reflects a long-lasting associative component of helplessness.
\end{abstract}

Exposure to inescapable shock produces a broad range of impairments, including learning deficits (interference effects; e.g., Hiroto \& Seligman, 1975; Maier, Albin, \& Testa, 1973; Minor, Jackson, \& Maier, 1984; Seligman \& Maier, 1967), motor-activity deficits (Anisman, deCatanzaro, \& Remington, 1978; Glazer \& Weiss, 1976; Jackson, Maier, \& Rapaport, 1978; Overmier \& Seligman, 1967), and neurochemical changes (e.g., Anisman, Glazier, \& Sklar, 1981).

Interference effects also have been shown to occur as the result of exposure to response-independent food (e.g., Job, 1987, 1988, 1989b, 1989c; Oakes, Rosenblum, \& Fox, 1982; Winefield, 1978). In light of the helplessness paradigm's use as an animal model of depression (see Overmier \& Hellhammer, 1988; Peterson, Maier, \& Seligman, 1993; Willner, 1984), research into appetitively induced helplessness effects is important both for the clarification of processes underlying these impairments and for assessing the extent to which this model of depression includes etiology in appetitive events.

Interference effects have been found to transfer across appetitive and aversive contexts (e.g., Rosellini, 1978; Rosellini \& DeCola, 1981; Sonoda, 1990; Sonoda, Okayasu, \& Hirai, 1991), suggesting that at least some common mechanisms are responsible for production of the appetitive and aversive effects. Furthermore, a number of parallels exist between aversive and appetitive interference effects. For example, behavioral immunization against the interference effect, where exposure to controllable shock or food deliveries prior to uncontrollability prevents subsequent impairments, has been achieved in both aversive (Brown, Howe, \& Jones, 1990; Hannum, Rosellini,

This research was supported by Australian Research Council Grant A79230942 to R.F.S.J. Correspondence should be addressed to R. F. S. Job, Department of Psychology, University of Sydney, Sydney, N.S.W., 2006, Australia (e-mail: soamesj@psychvax.psych.su.oz.au).
\& Seligman, 1976; Seligman \& Maier, 1967; Seligman, Rosellini, \& Kozak, 1975; Williams \& Maier, 1977) and appetitive (Mullins \& Winefield, 1977) paradigms. In addition, parallels exist between aversive and appetitive interference effects in terms of cognitive deficits (aversive, see Jackson, Alexander, \& Maier, 1980, and Rosellini \& Seligman, 1975; appetitive, see Job, 1989c), including failure on discrimination learning tests (aversive, see Irwin, Suissa, \& Anisman, 1980; appetitive, see Job, 1987). Furthermore, both aversive and appetitive helplessness treatments produce deficits in escape from frustration (aversive, see Rosellini \& Seligman, 1975; appetitive, see Job, 1989b), subsequent loss in body weight (aversive, see Dess, Minor, \& Brewer, 1989, and Dess, Raizer, Chapman, \& Garcia, 1988; appetitive, see Job, 1989a) and analgesia (aversive, see Jackson, Maier, \& Coon, 1979, and Maier, 1986; appetitive, see Hodgson \& Bond, 1991). One outcome of exposure to inescapable shock that remains to be tested in the appetitive paradigm is finickiness, or reduced consumption of bitter-tasting substances, such as quinine-adulterated water (Dess \& Chapman, 1990; Dess, Chapman, \& Minor, 1988; Prabhakar \& Job, 1996), quinine-adulterated food (Dess et al., 1989), or saccharinadulterated water (Dess, 1992, Experiments 1, 2B, and 4; Dess, 1993), but not unadulterated water. The finickiness effect also has been confirmed in a triadic design experiment, with escapably shocked and control rats not demonstrating the altered ingestive behavior of inescapably shocked counterparts (Job \& Barnes, 1995).

In examining another possible common outcome of aversive and appetitive helplessness treatments, the investigation of finickiness in the appetitive context may allow examination of the stressfulness of appetitive uncontrollability, as well as the mechanisms of finickiness itself. First, because fear is generated by pain (see Bolles \& Fanselow, 1980), providing response-independent food to a hungry rat is not dramatically fear arousing, as is uncontrollable electric shock. Thus, the production of fin- 
ickiness by uncontrollable appetitive events would indicate that such demonstrable fear is not a necessary condition for finickiness but that stress alone may be sufficient for its facilitation. A number of accounts of finickiness exist that do not depend on fear but that are based on stressinduced effects. These accounts include stress-induced enhancement of neophobia (Dess \& Chapman, 1990; Prabhakar \& Job, 1992), stress-induced neurochemical changes related to neophobia (Job \& Barnes, 1995), a stressinduced regulatory shift and more conservative foraging strategy (Dess, 1991), and stress-induced enhancement of the bitterness or unpleasantness of the quinine or saccharin (Job \& Barnes, 1995). Evidence suggests that uncontrollable appetitive treatment is stressful. It produces analgesia (Hodgson \& Bond, 1991) normally thought to be stress-induced (Maier, Sherman, Lewis, Terman, \& Lieberskind, 1983; Maier \& Watkins, 1991); controllable situations and controllable rewards are preferred over uncontrollable ones (Job \& Eccleston, 1992, 1996). Our observations during appetitive treatment indicate that food-deprived rats may even escape from the situation of uncontrollable food deliveries, whereas those receiving controllable deliveries do not escape. In fact, with early apparatus in which lids were not latched in place and with prolonged treatment, it was necessary to weigh down the Skinner box lids to prevent some yoked rats from leaping up the $32-\mathrm{cm}$-high wall, bumping off the lids, and jumping out. If appetitive uncontrollability does not produce finickiness, it will remain a possibility that pain and/or fear (and not stress alone) are necessary conditions for this altered ingestive behavior, although the potential contribution of other factors to such a null result cannot be ruled out. Nonetheless, finickiness following uncontrollable appetitive events would identify that fear is not a necessary condition for finickiness.

\section{EXPERIMENT}

The purpose of the present experiment was to examine whether finickiness is an outcome of exposure to appetitive uncontrollability. Earlier work had indicated the possibility that yoked rats exposed to uncontrollable food deliveries drink less quinine-adulterated water than do their response-contingent counterparts in a single-bottle test in the home cage (Ferguson \& Job, 1993). However, it was possible that failure to observe a clear effect in this case was due to poor generalization from the treatment apparatus to the home cage environment (where experience with food and water had entailed controllability). Furthermore, concurrent schedules of restricted food and water appeared to interfere with drinking patterns during testing. The present experiment, with these limitations in mind, used water reinforcement and a two-bottle choice test in the treatment apparatus.

The experiment involved measurement of intake of novel, quinine-adulterated water and tap water by rats for 4 days following a single session of exposure to uncontrollable, controllable, or no-water deliveries.

\section{Method}

Subjects. The subjects were 36 experimentally naive male Wistar rats, 90 days of age at the start of the experiment. The rats were housed individually in plastic boxes with metal grill lids in a room with a constant temperature of $21^{\circ} \mathrm{C}$ and a 12 -h light:dark cycle. All experimental manipulations occurred during the light period.

Solutions. The quinine solution consisted of $0.52 \mathrm{mg} / \mathrm{L}(0.52 \times$ $10^{-4 \%} \mathrm{w} / \mathrm{v}$ ) of quinine sulfate in tap water.

Apparatus. On all occasions, fluids were presented in propylene bottles with stainless steel spouts. Each Skinner box, measuring $29 \times 24 \times 28 \mathrm{~cm}$, was equipped with an aluminum dipper that raised a small cup of water to a hole, accessible to the rats, in a recessed section $2.5 \mathrm{~cm}$ above the grid floor in the middle of the front wall of the box. A 5-cm-wide response bar was located $3.5 \mathrm{~cm}$ to the left of the hole, protruding $2 \mathrm{~cm}$ from the front wall of each box. The side walls of the Skinner boxes were clear Plexiglas; other walls were stainless steel. The Skinner boxes were positioned in a darkened room and operated with Strawberry Tree software.

Procedure. Throughout the experiment, the subjects were maintained on a water schedule whereby they received access to water for $8 \mathrm{~min}$ at $0900 \mathrm{~h}$ and for a further $8 \mathrm{~min}$ at $1300 \mathrm{~h}$. At all times in their home cages, the rats had access to dry laboratory rat cubes. Using water reinforcement in treatment eliminated the necessity for implementation of a restricted food schedule that could have complicated the ingestive patterns being observed (Ferguson \& Job, 1993). For the first 5 days of the water schedule, the subjects received water for both the morning and the afternoon drinking sessions from a single stainless steel spout in their home cages. For the last 3 days of the initial water-restriction phase, the rats were placed in a Skinner box to receive their daily allowance from a single spout. This was done to ensure that the rats were accustomed to drinking from spouts in the Skinner box in readiness for fluid consumption during the tests (which were also conducted in the Skinner boxes). The rats were allocated to groups on the basis of total daily drinking averaged over these final 3 baseline days.

Treatment was conducted over 1 day. All subjects occupied a Skinner box for one session, commencing at $0900 \mathrm{~h}$. Water consumed during treatment substituted the morning drinking session. Treatment for each group was as follows:

Response contingent $(R C)$. The rats were able to earn up to 300 water rewards. Access to the dipper containing water was contingent upon performance of a barpress response on a schedule of continuous reinforcement. Shaping by successive approximation was employed. Initially, the dipper remained accessible for $18 \mathrm{sec}$ after response-contingent (RC) rats' barpresses in order to help ensure that the rats located the water source; as each rat learned the contingency between barpressing and water access, the dipper elevation time was gradually reduced to $2 \mathrm{sec}$. (Four animals that did not earn the target of 300 water exposures, and their yoked counterparts, were eliminated from the study in order to ensure that all rats had received the full treatment. Subsequent analyses of test results including those of these animals revealed the same statistically significant results as reported in this paper.)

Yoked $(\mathrm{Y})$. The schedule of water delivery to yoked $(\mathrm{Y})$ subjects was determined by the responses of their RC counterparts; although the bar was present, barpresses had no programmed consequences.

Control (C). Control (C) rats received access to water for $8 \mathrm{~min}$ from a stainless steel spout in their home cage immediately prior to the treatment session such that all subjects were equated approximately in terms of water consumption; the average amount consumed in $8 \mathrm{~min}$ was equivalent to 300 dipperfuls. $\mathrm{C}$ rats remained in the Skinner box for the amount of time taken by their RC counterparts to earn up to 300 water reinforcers but received no water. Bars were present, but barpresses had no scheduled outcome.

At $1300 \mathrm{~h}$, in their home cage, all subjects were given access to water from a single spout for $8 \mathrm{~min}$ in keeping with the procedure established during the initial deprivation phase. 
For the test phase, all rats were placed in the Skinner box at $0900 \mathrm{~h}$ on the morning following the treatment day and, for $8 \mathrm{~min}$, were given access to two spouts, protruding side by side from the recess where water was previously presented. One spout contained water, and the other contained the novel quinine solution. A two-bottle choice test was employed (rather than having quinine available only in the morning and water only in the afternoon; e.g., Dess, Chapman, \& Minor, 1988) in order to avoid the possibility of differential levels of thirst (or stress) at morning and afternoon testing times affecting the proportionate intake of quinine and water. Testing was conducted in the treatment apparatus to overcome the rats' possible discrimination between the Skinner box and the home cage, which is likely in an appetitive paradigm given rats' previous experience with controllable food in the home-cage environment, as noted above (see Job, 1988, p. 459). The subjects were returned to their home cages immediately after the 8-min drinking session. This process was repeated for the afternoon drinking session at $1300 \mathrm{~h}$. Positions of the spouts were counterbalanced between subjects and test sessions. Following exposure to inescapable shock, the quinine finickiness observed by Dess, Chapman, and Minor (1988) dissipated within $48 \mathrm{~h}$. In the present experiment, the test procedure was carried out for 4 days in order to examine whether any appetitively induced finickiness effect mimicked the 24-48-h time course of shockinduced quinine finickiness and many other helplessness-related deficits or persisted for longer.

Quinine consumption was recorded as a proportion of total daily intake.

\section{Results}

Figure 1 presents the results in terms of quinine consumption as a percentage of total daily fluid intake. The pattern of results shows that finickiness did occur in the $Y$ rats. A 3 (groups) $\times 4$ (test days) analysis of variance (ANOVA) revealed that intake of quinine, relative to water, differed between groups across the 4 test days $[F(2,25)=$ $7.214, p=.002]$. Across all test days, planned contrasts revealed that the $\mathrm{Y}$ group drank less than did the $\mathrm{RC}$ $[F(1,14)=10.221, p=.002]$ and $C[F(1,18)=12.023$, $p=.001]$ groups, which did not differ $[F(1,18)=0.001$, $p>.05]$. There was no test day main effect $[F(3,25=0.617$, $p>.05]$ and no group $\times$ test day interaction $[F(6,25=$ $0.889, p>.05]$.

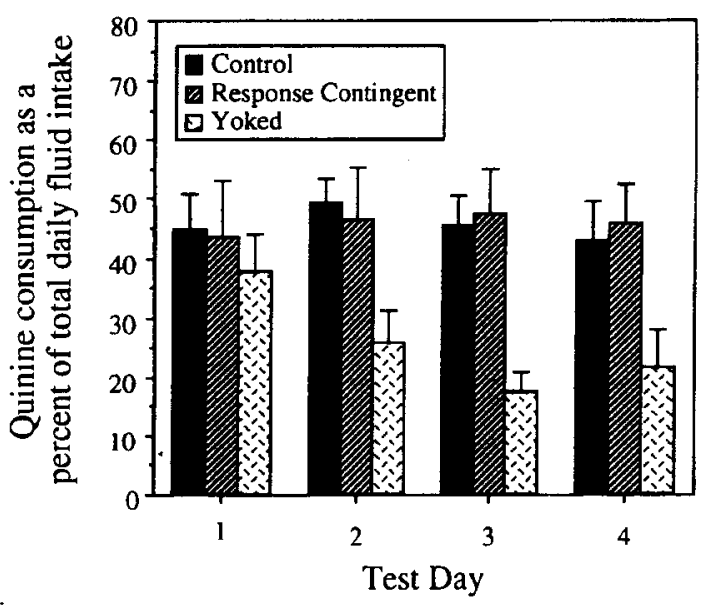

Figure 1. Mean quinine consumption as a percent of total daily fluid intake for each group across the 4 test days.
As indicated in Figure 1, these group differences were not statistically significant on the first test day within $24 \mathrm{~h}$ of treatment $[F(2,25)=0.250, p>.05]$. While means were in the expected direction, $Y$ rats did not drink a significantly lower proportion of quinine than did RC or $\mathrm{C}$ rats on this day [larger $F(1,18)=0.475, p>.05]$. RC and $C$ groups did not differ significantly $[F(1,18)=0.017$, $p>.05]$.

Absolute daily fluid intake means are indicated in Figure 2, with bars separated into total fluid consumption in the morning (below line) and afternoon (above line) drinking sessions. Morning and afternoon total fluid intakes did not differ significantly $(p>.05)$, hence the pooling of measures into a daily result. Groups did not differ in terms of how much total fluid (water plus quinine) they consumed on any of the 4 test days ( $p>.05$, in all cases). There were no group differences in morning or afternoon intakes ( $p>.05$, across 4 test days).

\section{Discussion}

The present results suggest that exposure to uncontrollable appetitive events produces finickiness. Since the groups did not differ in terms of total daily fluid intake, the yoked rats' lower consumption of quinine as a proportion of total daily drinking reflected finickiness about the quinine solution rather than an overall effect on fluid intake. The effect persisted for at least the 4-day time course of the test phase, unlike the finickiness obtained by Dess, Chapman, and Minor (1988), which had dissipated by the 3rd test day. Absence of a significant finickiness effect on the 1st test day may have been the result of insufficient statistical power, although other explanations exist. Examination of the data from the 1st test session indicates that all rats drank from both available bottles and, therefore, were exposed to the taste of both water and the quinine solution. What is not known is whether they drank, by chance, from the quinine bottle in the first instance and, having never experienced the availability of two spouts previously, were slow to detect the choice available to them. Alternatively, this failure of the 1st test day effect to achieve significance may be characteristic of appetitively induced finickiness. The inconsistency of this finding with evidence of finickiness $24 \mathrm{~h}$ after exposure to uncontrollable shock (Dess, Chapman, \& Minor, 1988) may reflect different levels of anxiety induced by appetitive and aversive treatments. Perhaps exposure to uncontrollable appetitive events produces less anxiety and, therefore, less initial sensitivity to bitter tastants than does inescapable shock treatment.

The prolonged time course of finickiness in this experiment raises the possibility that the mechanisms underlying other helplessness effects that dissipate within 24-72 h (e.g., shuttle escape deficit) and finickiness may not be the same. However, a number of other effects do not show dissipation in 24-72 h (e.g., suppresssion of exploratory behavior, see Bruto \& Anisman, 1983; running wheel activity, see Desan, Silbert, \& Maier, 1988, and Maier, Silbert, Woodmansee, \& Desan, 1990; reduced aggression 


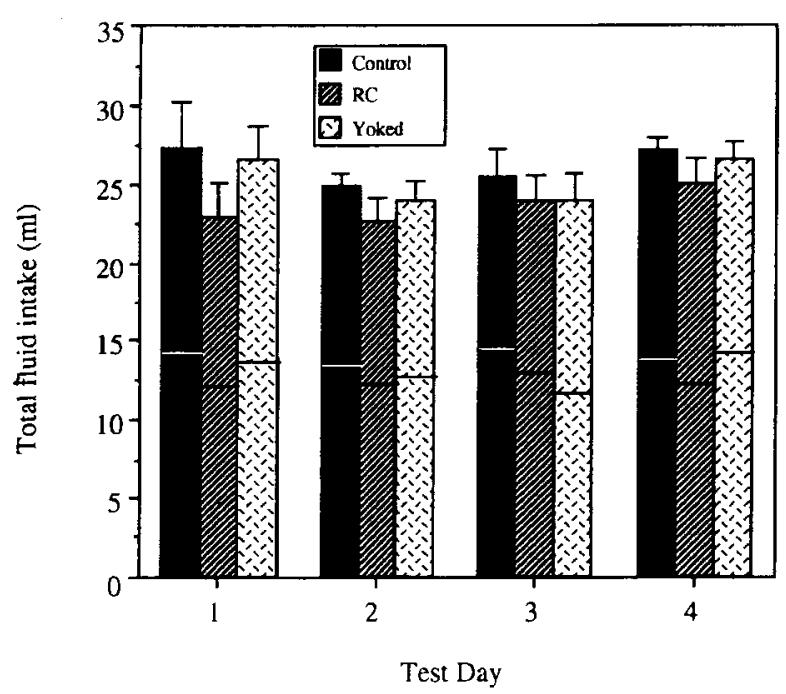

Figure 2. Mean absolute fluid intake (water plus quinine) for each group across the 4 test days. Each bar is divided into mean consumption during morning (below line) and afternoon (above line) drinking sessions.

toward colony intruders, see Williams, 1982; altered maternal behavior, see Williams, 1984; analgesia, see Maier \& Watkins, 1991). Possibly, the mechanism controlling finickiness is the mechanism underlying these longer lasting effects. Dess, Chapman, and Minor (1988) point out that, by design, their testing of quinine finickiness does not clearly identify the time course of the effect, since intake on each test is confounded by the quinine exposure afforded by prior tests. The present study encountered the same procedural issue but, in this case, prior exposure on earlier tests did not appear to diminish the degree of finickiness. Possibly, the aversive properties of bitter-tasting quinine are more likely to maintain rats' suppressed intake when offered in the treatment apparatus where stressinducing cues are present. If testing had been conducted in a context bearing no resemblance to the treatment apparatus, the finickiness effect may have dissipated more quickly. Home-cage testing would throw light on the importance of the role of conditioned stress in the production of finickiness and other appetitively induced effects on vegetative function.

The clear emergence of finickiness in this experiment implies that fear and/or pain are not necessary conditions for alteration of ingestive behavior and that stress generated by exposure to uncontrollable appetitive events is sufficient for the production of a finickiness effect. However, the meaning of uncontrollability within the appetitive paradigm is somewhat different from the meaning of uncontrollability in the aversive situation. A rat's experience of inescapable shock is entirely independent of its behavior. However, in the case of presentation of response-independent water or food, a rat still controls whether or not it will ingest the reward. This raises two related issues: First, are the groups equally exposed to the reward? Second, is there any real uncontrollability in- volved? While exact records of water ingestion by each rat during the treatment session were not kept for the present experiment, constant observation revealed that rats in both yoked and response-contingent groups drank from the dipper virtually every time it was elevated. Therefore, differences in water intake during treatment between animals in these groups, if any, would not have had a significant bearing on subsequent fluid consumption. In relation to the second issue, the requirement for ingestion does not overcome the uncontrollability of reward delivery itself. Conceptually, it would seem that the option not to consume the reward is only relevant in a state of satiation such that genuine options exist that offer control (the options of consuming or not consuming without suffering hunger or thirst). In a state of deprivation, as existed in our subjects, the reward is reliably consumed, and satiation is not reached in any session. Thus, reward delivery is the critical limiting factor, and it is uncontrollable. This also would seem to be the most ecologically valid version of appetitive uncontrollability: For animals in the wild, the central concern is obtaining food and water, not whether or not to consume it. The critical role of delivery is supported empirically by observations of effects of uncontrollable reward deliveries, which, despite the option to ingest or not, produce effects that mimic those of uncontrollable shock (Job, 1987, 1988, 1989b, 1989c; Mullins \& Winefield, 1977; Sonoda et al., 1991; Winefield, 1978).

Another factor of major importance in helplessness research that may have influenced the expression of finickiness in the present experiment is predictability. Activation of the dipper generated a sound that would have alerted the rats in the yoked condition to the fact that water was about to be presented. Therefore, the finickiness observed might be seen to reflect the effect of uncontrollability, but not unpredictability, of appetitive events. Aversive studies have shown that the usual performance deficits following exposure to uncontrollable shocks are attenuated when shocks, shock termination, or shock-free periods are predictable (e.g., Jackson \& Minor, 1988; Minor, Trauner, Lee, \& Dess, 1990; Seligman, 1968; Seligman, Maier, \& Solomon, 1971). Accordingly, predictability of the water deliveries might have been expected to alleviate, to some extent, effects such as finickiness. However, typical interference effects have been produced following exposure to uncontrollable food deliveries despite the fact they are signaled, similarly, by the click of the magazine (Job, 1987, 1988, 1989b, 1989c). This finding and the present results imply that predictability is not a relevant factor in the production of finickiness. Conversely, a 1.5 -sec tone predicting uncontrollable food deliveries eliminates subsequent shuttle escape learning in rats (Sonoda \& Hirai, 1992), suggesting that the failure of the unintentionally predictive signal to serve a protective role in the present experiment (and all other appetitive cases) possibly relates to its short duration $(<1.0 \mathrm{sec})$ and close temporal proximity to the reward, which may render it inefficient in preventing later impairments. 
The present results are of theoretical relevance. The persistence of the finickiness effect across 4 test days (and possibly longer, since testing was not continued) supports the notion that finickiness reflects an associative mechanism of stress, which persists beyond the nonassociative deficits that appear to be crucial in the production of performance impairments following inescapable shock and that diminish 24-72 $\mathrm{h}$ after treatment (see Minor, Dess, \& Overmier, 1991; Weiss et al., 1981). The direct neurochemical effects of inescapable shock, which, when combined with associative effects, yield subsequent deficits (Minor et al., 1991; Weiss et al., 1981), do not appear to be a necessary condition for the production of finickiness (but see Job \& Barnes, 1995, for defense of neurochemical accounts of finickiness). However, it may be the case that finickiness can only be established in the 24-72 $\mathrm{h}$ window but persists once established. Clear identification of finickiness independent of dissipation with time would require an initial test for finickiness at least $72 \mathrm{~h}$ after treatment.

Without producing outright fear of an aversive event, the nonetheless stressful appetitive uncontrollability treatment apparently produces finickiness. The present results suggest that the more severe stressors of pain and fear and exposure to uncontrollable aversive events are not necessary conditions for finickiness. However, alternative accounts in terms of stress-induced neurochemical changes (Job \& Barnes, 1995), the regulatory shift hypothesis (Dess, 1991), and stress-enhanced bitterness (Job \& Barnes, 1995) - all of which rest on stress induction as the independent variable - are consistent with the present results. If these mechanisms (regulatory shift or stressenhanced bitterness) were long-lasting, these also may explain the persistence of finickiness in the present case. However, an account of the difference between the appetitive and aversive cases would be required. The present results do not favor an explanation in terms of stressinduced enhancement of neophobia (Dess \& Chapman, 1990; Prabhakar \& Job, 1992), since the yoked rats did not increase their quinine intake over the course of the testing period. Thus, finickiness persisted despite the increasing familiarity of the quinine brought about by prior tests.

The finding that finickiness about quinine-adulterated water follows exposure to uncontrollable appetitive events demands that care be taken in the interpretation of results where novel (and possibly bitter) food is the reinforcer in appetitive tests of helplessness. The concern applies to experiments in which aversive-appetitive transfer is tested, rather than appetitive-appetitive experiments in which the food has become familiar before testing begins. The limitation of this concern to novel food in the test arises from the finding that preexposure to quinine eliminates finickiness (Job \& Barnes, 1995), whereas in the present experiment repeated quinine exposure after the treatment (through successive tests) did not reduce finickiness.

The suggestion that finickiness reflects the associative component of helplessness has a number of important implications for the treatment of eating disorders asso- ciated with depression (Dess, 1991; Job \& Barnes, 1995): Uncontrollable food deliveries may contribute to the problems of finicky eating and depressed affect. Importantly, the present finding adds to the parallels between the effects of appetitive and aversive uncontrollability and so supports the extension of the uncontrollabilitybased animal model of psychopathology to effects of uncontrollable appetitive events.

\section{REFERENCES}

Anisman, H., deCatanzaro, D., \& Remington, G. (1978). Escape performance deficits following exposure to inescapable shock: Deficits in motor response maintenance. Journal of Experimental Psychology: Animal Behavior Processes, 4, 197-218.

anisman, H., Glazier, S. J., \& Sklar, L. (1981). Cholinergic influences on escape deficits produced by uncontrollable stress. Psychopharmacology, 74, 81-87.

Bolles, R. C., \& Fanselow, M. S. (1980). A perceptual-defensiverecuperative model of fear and pain. Behavioral \& Brain Sciences, 3 , 291-323.

Brown, G. E., Howe, A. R., \& Jones, T. E. (1990). Immunization against learned helplessness in the cockroach (Periplaneta americana). Psychological Reports, 67, 635-640.

BRUto, V., \& ANISMAN, H. (1983). Alterations of exploratory patterns induced by uncontrollable shock. Behavioral \& Neural Biology, 37, 317-325.

Desan, P. H., Silbert, L. H., \& Maier, S. F. (1988). Long-term effects of inescapable stress on daily running activity and antagonism by desipramine. Pharmacology, Biochemistry \& Behavior, 30, 21-29.

DESs, N. K. (1991). Ingestion and emotional health. Human Nature, 2, 235-269.

DEss, N. K. (1992). Divergent responses to saccharin and sucrose availability after stress in rats. Physiology \& Behavior, 52, 115-125.

DESs, N. K. (1993). Saccharin's aversive taste in rats: Evidence and implications. Neuroscience \& Biobehavioral Reviews, 17, 359-372.

Dess, N. K., \& ChaPMAN, C. D. (1990). Individual differences in taste, body weight, and depression in the "helplessness" rat model and in humans. Brain Research Bulletin, 24, 669-676.

Dess, N. K., Chapman, C. D., \& Minor, T. R. (1988). Inescapable shock increases finickiness about drinking quinine-adulterated water in rats. Learning \& Motivation, 19, 408-422.

Dess, N. K., Minor, T. R., \& Brewer, J. (1989). Suppression of feeding and body weight by inescapable shock: Modulation by quinine adulteration, stress reinstatement, and controllability. Physiology \& Behaviour, 44, 483-490.

Dess, N. K., Raizer, J., Chapman, C., \& GarCia, J. (1988). Stressors in the learned helplessness paradigm: Effects on body weight and conditioned taste aversion in rats. Physiology \& Behavior, 44, 483-490.

Ferguson, E. C., \& Job, R. F. S. (1993). The appetitive learned helplessness paradigm and finickiness [Abstract]. Australian Journal of Psychology, 45, 113.

Glazer, H. I., \& WeISS, J. M. (1976). Long-term interference effect: An alternative to "learned helplessness." Journal of Experimental Psychology: Animal Behavior Processes, 2, 201-213.

Hannum, R. D., Rosellini, R. A., \& Seligman, M. E. (1976). Learned helplessness in the rat: Retention and immunization. Developmental Psychology, 12, 449-454.

Hiroto, D. S., \& Seligman, M. E. P. (1975). Generality of learned helplessness in man. Journal of Personality \& Social Psychology, 31, 311-327.

Hodgson, D. M., \& Bond, N. W. (1991). Control of food delivery in food-deprived rats mediates analgesia. Behavioural Brain Research, 44, 205-209.

IRwin, J., Suissa, A., \& ANisman, H. (1980). Differential effects of inescapable shock on escape performance and discrimination learning in a water escape task. Journal of Experimental Psychology: Animal Behavior Processes, 6, 21-42.

Jackson, R. L., Alexander, J. H., \& Maier, S. F. (1980). Learned helplessness, inactivity, and associative deficits: Effects of in- 
escapable shock on response choice escape learning. Journal of Experimental Psychology: Animal Behavior Processes, 6, 1-20.

JACKSON, R. L., MAIER, S. F., \& COON, D. J. (1979). Long-term analgesic effects of inescapable shock and learned helplessness. Science, 206, 91-93.

JACKSON, R. L., Maier, S. F., \& RAPAPORT, P. M. (1978). Exposure to inescapable shock produces both activity and associative deficits in the rat. Learning \& Motivation, 9, 69-98.

JACKSON, R. L., \& MINOR, T. R. (1988). Effects of signalling inescapable shock on subsequent escape learning: Implications for theories of coping and "learned helplessness." Journal of Experimental Psychology: Animal Behavior Processes, 14, 390-400.

JOB, R. F. S. (1987). Learned helplessness in an appetitive discrete-trial T-maze discrimination test. Animal Learning \& Behavior, 15, 342-346.

JoB, R. F. S. (1988). Interference and facilitation produced by noncontingent reinforcement in the appetitive situation. Animal Learning \& Behavior, 16, 451-460.

JoB, R. F. S. (1989a, April). Learned helplessness in the appetitive situation: A resolution of inconsistent results in terms of procedures and dependent variables. Paper presented at the Fifteenth Annual Australian Experimental Psychology Conference, Jamberoo.

JOB, R. F. S. (1989b). Response independent food and escape from frustration. In N. W. Bond \& D. A. T. Siddle (Eds.), Psychobiology: Issues and applications. Amsterdam: North-Holland.

JoB, R. F. S. (1989c). A test of the proposed mechanisms underlying the interference effect produced by noncontingent food presentation. Learning \& Motivation, 20, 153-177.

JoB, R. F. S., \& Barnes, B, (1995). Stress and consumption: Inescapable shock, neophobia and quinine finickiness in rats. Behavioral Neuroscience, 109, 106-116.

JoB, R. F. S., \& ECCLESTON, J. M. (1992). The effects of uncontrollability of food deliveries on learning and food or place preferences [Abstract]. International Journal of Psychology, 27, 437.

Joв, R. F. S., \& EcCleston, J. M. (1996). Avoiding helplessness: Preferences for controllable rather than uncontrollable locations and foods. Manuscript in preparation.

MAIER, S. F. (1986). Stressor controllability and stress-induced analgesia. In D. D. Kelly (Ed.), Stress-induced analgesia (Annals of the New York Academy of Sciences, Vol. 467, pp. 55-72). New York: New York Academy of Sciences.

Maier, S. F., Albin, R. W., \& TesTa, T. J. (1973). Failure to learn to escape in rats previously exposed to inescapable shock depends on the nature of the escape response. Journal of Comparative \& Physiological Psychology, 85, 581-592.

Majer, S. F., Sherman, J. E., Lewis, J. W., Terman, G. W., \& LiebersKIND, J. C. (1983). The opioid/nonopioid nature of stress-induced analgesia and learned helplessness. Journal of Experimental Psychology: Animal Behavior Processes, 9, 80-90.

Maier, S. F., Silbert, L. H., Woodmansee, W. W., \& Desan, P. H. (1990). Adinolam both prevents and reverses the long-term reduction of daily activity by inescapable shock. Pharmacology, Biochemistry \& Behavior, 36, 767-773.

MAIER, S. F., \& WATKINS, L. R. (1991). Conditioned and unconditioned stress-induced analgesia: Stimulus preexposure and stimulus change. Animal Learning \& Behavior, 19, 295-304.

Minor, T. R., Dess, N. K., \& Overmier, J. B. (1991). Inverting the traditional view of "learned helplessness": Reinterpretation in terms of anxiety and modulator operations. In M. R. Denny (Ed.), Fear, avoidance, and phobias: A fundamental analysis (pp. 87-133). Hillsdale, NJ: Erlbaum.

MinOR, T. R., JACKSON, R. L., \& MAIER, S. F. (1984). Effects of taskirrelevant cues and reinforcement delay on choice escape learning following inescapable shock: Evidence for a deficit in selective attention. Journal of Experimental Psychology: Animal Behavior Processes, 10, 543-556.

Minor, T. R., Trauner, M. A., LeE, C. Y., \& Dess, N. K. (1990). Modelling signal features of escape response: Effects of cessation conditioning in "learned helplessness" paradigm. Journal of Experimental Psychology: Animal Behavior Processes, 16, 123-136.

Mullins, G. P., \& Winefield, A. H. (1977). Immunization and helplessness phenomena in the rat in a nonaversive situation. Animal Learning \& Behavior, 5, 281-284.
OAKes, W. F., Rosenblum, J. L., \& Fox, P. E. (1982). "Manna from heaven": The effect of noncontingent appetitive reinforcers on learning in rats. Bulletin of the Psychonomic Society, 19, 123-126.

Overmier, J. B., \& Hell hammer, D. H. (1988). The learned helplessness model of human depression. Animal Models of Psychiatric Disorder, 2, 177-202.

Overmier, J. B., \& Seligman, M. E. P. (1967). Effects of inescapable shock upon subsequent escape and avoidance learning. Journal of Comparative \& Physiological Psychology, 63, 23-33.

Peterson, C., Maier, S. F., \& Seligman, M. E. P. (1993). Learned helplessness: A theory for the age of personal control. New York: Oxford University Press.

Prabhakar, T., \& Job, R. F. S. (1992). The effects of order of shock duration on debilitation (learned helplessness) in rats [Abstract]. International Journal of Psychology, 27, 434.

Prabhakar, T., \& Job, R. F. S. (1996). The effects of order of shock durations on learned helplessness in rats. Animal Learning \& Behavior, 24, 175-182.

Rosellini, R. A. (1978). Inescapable shock interferes with the acquisition of an appetitive operant. Animal Learning \& Behavior, 6, 155 . 159.

Rosellini, R. A., \& DeColA, J. P. (1981). Inescapable shock interferes with the acquisition of a low-activity response in an appetitive context. Animal Learning \& Behavior, 9, 487-490.

Rosellini, R. A., \& Seligman, M. E. P. (1975). Frustration and learned helplessness. Journal of Experimental Psychology: Animal Behavior Processes, 104, 149-157.

Seligman, M. E. P. (1968). Chronic fear produced by unpredictable electric shock. Journal of Comparative \& Physiological Psychology, 66, 402-411.

Seligman, M. E. P., \& MaIER, S. F. (1967). Failure to escape traumatic shock. Journal of Experimental Psychology, 74, 1-9.

Seligman, M. E. P., Maier, S. F., \& Solomon, R. L. (1971). Unpredictable and uncontrollable aversive events. In F. R. Brush (Ed.), Aversive conditioning and learning (pp. 347-400). New York: Academic Press.

Seligman, M. E. P., Rosellini, R. A., \& Kozak, M. (1975). Learned helplessness in the rat: Reversibility, time course and immunization. Journal of Comparative \& Physiological Psychology, 88, 542547.

SonOda, A. (1990). Effect of uncontrollable shock on subsequent appetitive discrimination learning in rats. Japanese Journal of Psychonomic Science, 8, 95-100. (Japanese, with English abstract)

Sonoda, A., \& Hiral, H. (1992). The role of predictability in preventing escape deficits following loss of control over food acquisition. Animal Learning \& Behavior, 20, 427-430.

Sonoda, A., OKayasu, T., \& Hirai, H. (1991). Loss of controllability in appetitive situations interferes with subsequent learning in aversive situations. Animal Learning \& Behavior, 19, 270-275.

Weiss, J. M., Goodman, P. A., Losito, B. G., Corrigan, S., Charry, J. M., \& BAILEY, W. H. (1981). Behavioral depression produced by an uncontrollable stressor: Relationship to norepinephrine, dopamine, and serotonin levels in various regions of rat brain. Brain Research Reviews, 3, 167-205.

WILLIAMS, J. L. (1982). Influence of shock controllability by dominant rats on subsequent attack and defensive behaviors toward colony intruders. Animal Learning \& Behavior, 10, 305-313.

Williams, J. L. (1984). Influence of postpartum shock controllability on subsequent maternal behavior in rats. Animal Learning \& Behavior, 12, 209-216.

Williams, J. L., \& MAIER, S. F. (1977). Transituational immunization and therapy of learned helplessness in the rat. Journal of Experimental Psychology: Animal Behavior Processes, 3, 240-252.

WILLNER, P. (1984). The validity of animal models of depression. Psychopharmacology, 83, 1-22.

WINEFIELD, A. H. (1978). The effect of prior random reinforcement on brightness discrimination learning in rats. Quarterly Journal of Experimental Psychology, 30, 113-119.

(Manuscript received December 12, 1994; revision accepted for publication February 7,1996 .) 